\title{
Talcott Parsons: apontamentos para uma análise institucional ${ }^{1}$
}

\section{Talcott Parsons: notes to institutional analysis}

\author{
Andressa Silvério Terra França ${ }^{2}$
}

\section{RESUMO}

O artigo discute as principais contribuições de Talcott Parsons para o pensamento sociológico contemporâneo, destacando as significativas influências de sua teoria nas abordagens institucionalistas. Pretende-se indagar quais as contribuições desse autor à teoria institucional que ainda perduram e responder algumas questões básicas tais como: porque este teórico da sociologia americana não deve ser esquecido? A compreensão de suas idéias ajuda-nos a entender o que tem sido hoje escrito na teoria neoinstitucional? Quais as seriam diferenças e as semelhanças existentes entre o seu estrutural-funcionalismo e as abordagens institucionalistas do século $X X$ ? E neste sentido, quais seriam as principais contribuições de Talcott Parsons à Teoria Sociológica das Instituições? Pretende-se demonstrar que esse precursor trouxe contribuições importantes para o que se entende por "instituições" na atualidade, principalmente ao enfatizar a relevância em se considerar a influência de padrões socioculturais e padrões normativos que orientam a conduta dos indivíduos.

Palavras-chave: Sociologia Parsoniana. Novo Institucionalismo. Instituições. Padrões normativos. Ambiente sociocultural.

\section{ABSTRACT}

The article discusses the main contributions of Talcott Parsons to contemporary sociological thought, highlighting the significant influence of his theory in the institutionalists approaches. It is asking that the contributions of institutional theory that the author still persist and answer some basic questions such as: why this theorist of American sociology it should not be forgotten? The understanding of his ideas helps us to understand what has been written today in theory neoinstitucional? What would be the differences and similarities between the structural-functionalism and approaches institutionalists of the twentieth century? In this sense, which are the main contributions of Talcott Parsons to a Social Theory of Institutions? It is shown that this precursor has important contributions to what is meant by "institutions" at present, mainly to emphasize the importance in considering the influence of sociocultural patterns and normative rules that guide the conduct of individuals subject to them.

\footnotetext{
${ }^{1}$ Este trabalho é resultado das discussões realizadas a partir da disciplina de "Tópicos Avançados em Teorias Sociológicas Clássicas", do programa de pós-graduação em Sociologia da Universidade Federal do Paraná (UFPR).

${ }^{2}$ Bacharel em Ciências Sociais, possui mestrado em sociologia (UFPR), atualmente é doutoranda em sociologia, no Programa de Pós-Graduação em Sociologia (UFPR), onde integra grupo de pesquisa na área de sociologia e política. andressastf@gmail.com
} 
Keywords: Parsons Sociology. New institutionalism. Institutions. Normative rules. Social environment.

\section{INTRODUÇÃO}

Uma das teorias que vêm sendo amplamente utilizadas no entendimento dos processos sociais é a chamada "Teoria Institucional", também denominada "neoinstitucionalista", em sua vertente mais recente. Essa abordagem vem sendo empregada há alguns anos na Sociologia (e, em particular, na Sociologia das Organizações), Ciência Política e Economia. Entretanto, como se pode notar, continua a ser uma das mais controversas em termos de concepção teórica e de aplicação prática.

Segundo W. Richard Scott (1995), a origem do que nos dias atuais se intitula como 'abordagem institucional' — ou "novo institucionalismo" — remonta a alguns conceitos formulados no final do século XIX, sob o impulso dos debates empreendidos na Alemanha acerca do método científico. Nas antigas tradições da Economia (representada por Thorstein Veblen, John Commons e Westley Mitchell), da Sociologia de Émile Durkheim e de Max Weber, da Ciência Política e de suas reações aos excessos do behaviorismo e, mais tarde, dos estudos funcionalistas de Talcott Parsons e Philip Selznick, acha-se uma tentativa de compreensão da relação existente entre política, economia e sociedade. Nesse contexto, encontra-se a base do renovado empenho pela procura de respostas para as eternas dúvidas sobre 0 modo como as escolhas sociais são modeladas, mediadas e canalizadas em arranjos institucionais (FONSECA, 2003). Outrossim, de acordo com Walter Powell e Paul DiMaggio (1991), a etnometodologia de Harold Garfinkel e o construtivismo social de Peter Berger e Thomas Luckmann seriam considerados os microfundamentos oficiais da perspectiva supra citada.

Richard Colignon (1997) e Maria Misoczky (2003) alertam para o fato de que a base fundamental tanto do 'novo institucionalismo' (assim como o da velha teoria institucional) está assentada na teoria parsoniana dos sistemas. Os autores retomam uma passagem de Wolf Heydebrand, quando este afirma que: "while the scope has been widened, its internal coherence and precision has been weakened by incorporating various strands of traditional sociology, although omitting the most 
obvious progenitor of institutionalism: Parsonian systems theory" (HEYDEBRAND, 1989, p.333).

Se tal afirmação é verdadeira, este ensaio pretende indagar quais as contribuições de Parsons à teoria institucional que ainda perduram, e responder algumas questões básicas, a saber: porque este teórico da sociologia americana não deve ser esquecido? A compreensão de suas ideias nos ajuda a entender o que tem sido hoje escrito na teoria neo-institucional? Quais as seriam diferenças e as semelhanças existentes entre o seu estrutural-funcionalismo e as abordagens institucionalistas do século $X X$ ? $E$, nesse sentido, quais seriam as principais contribuições de Talcott Parsons à Teoria Sociológica das Instituições?

Tal é o objetivo deste trabalho. Mais do que discutir ou contrapor o "velho" e o "novo" institucionalismo, este texto busca apenas refletir, com base nas perguntas acima formuladas, sobre o papel de um dos principais "precursores" (senão o principal) da teoria institucional. Para atingir este objetivo, dividimos o texto em três partes fundamentais. Inicialmente, buscamos contextualizar a obra de Talcott Parsons em seu momento histórico e no campo sociológico para, posteriormente, posicionar o elemento "instituição" na estrutura de seu pensamento. Na seqüência, por meio da exposição dos seus conceitos fundamentais, pretendemos identificar os elementos centrais que caracterizam a sua suposta pretensão com uma "teoria das instituições". Na terceira parte, por fim, expomos os pressupostos fundamentais da teoria neo-institucional na atualidade e sua relação com a teoria parsoniana. A última parte está reservada às conclusões das considerações.

\section{O ELEMENTO “INSTITUIÇÃO” NA SOCIOLOGIA DE TALCOTT PARSONS}

Talcott Parsons (1902-1979) é apontado, por admiradores e críticos, como um dos principais teóricos do pensamento sociológico do nosso tempo. Alguns até chegam a apontar que ele teria sido uma das figuras responsáveis por colocar a sociologia em um lugar de destaque no meio acadêmico norte-americano (MAYHEN, 1982).

Se Parsons ocupa um lugar de destaque entre os sociólogos norteamericanos é devido justamente ao tipo de revolução teórica que realizou em uma 
sociologia até então marcada por estudos essencialmente de natureza empírica. Como salienta Guy Rocher (1976), os trabalhos empíricos da sociologia americana da época pertencem principalmente a dois tipos de pesquisa. A primeira pode ser resumida à famosa Escola de Chicago que possuía como características fundamentais a "[...] confiança na pesquisa sociológica e seu desejo de aplicar métodos cada vez mais rigorosos a um número cada vez maior de assuntos" (ROCHER, 1976, p.21). Além disso, marca esse grupo a inexistência de uma teoria ou doutrina comum, o fato de terem o ambiente urbano como foco de interesse e a atenção especial voltada aos aspectos conflituais ou patológicos. O segundo grupo de pesquisas empíricas é composto pelas chamadas monografias urbanas, que retratavam a vida americana da época. Parsons, ao contrário, era muito mais voltado para a abstração do que para a pesquisa empírica.

Suas preocupações intelectuais eram outras. Sua crítica é outra. Vivenciando um dos períodos mais conturbados da história (contexto marcado pela crise econômica do capitalismo, pela tensão do entre as duas guerras, e pela ascensão de regimes nazi-fascistas ao poder), esse pensador contraria a tendência seguida por seus contemporâneos e passa a dedicar todo o seu esforço na construção de um quadro conceitual e teórico consistente, destinado a conferir à sociologia o status de ciência autêntica.

Para Parsons, o objeto da sociologia remete à "teoria dos sistemas sociais", uma vez que "se ocupa dos fenômenos da institucionalização dos padrões de orientações de valor no sistema social, das condições dessa institucionalização e das mudanças dos padrões, das condições de conformidade e desvio em relação a esses padrões, e dos processos motivacionais na medida em que estão implicados em todos eles" (PARSONS, 1982, p.507).

Fortemente influenciado pelos sociólogos europeus, principalmente por Durkheim e Weber, por filósofos ingleses e economistas "institucionalistas", Parsons se destaca por incorporar elementos novos que tornam seu pensamento original e instigante, sobretudo pela importância que dedica à ação dos atores sociais na configuração do sistema social. Ainda segundo Rocher (1976), uma das principais contribuições de Parsons, sobretudo em The Strutucture of Social Action (1937), foi a de fazer sobressair que na sua ação o homem se propõe metas, exprime 
vontades, obedece a motivações e que uma teoria geral da ação humana deve poder integrar todos esses elementos da realidade.

São três os sistemas gerais da ação pelos quais se interessa a teoria parsoniana (PARSONS, 1937; 1973a; 1973b; 1982). Cada um deles é dotado de uma estrutura própria e não pode ser reduzido aos demais. Constituem-se de conjuntos organizados que orientam a conduta de um ator individual, ou de uma coletividade, frente aos objetos de uma situação. O primeiro desses sistemas - o cultural - compreende padrões de orientação de valor: símbolos, normas, crenças etc. que guiam a conduta e oferecem opções segundo as quais os indivíduos empreendem sua seleção de fins e meios ${ }^{3}$. Os sistemas culturais formam a base dos sistemas social e de personalidade, uma vez que possibilitam o compartilhamento de sistemas simbólicos, sentimentos, padrões de conduta, normas etc. Os sistemas de personalidade e social correspondem à ação motivada, ligada a interesses, sejam eles individuais ou coletivos. O primeiro é aquele que organiza as orientações e motivações da ação de um ator individual, tratando de otimizar as gratificações e, ao mesmo tempo, minimizar as privações; são disposições de necessidade que correspondem a uma tendência da personalidade a mobilizar o indivíduo para que atenda às suas carências, sejam elas de caráter biológico ou social. Um sistema social consiste em uma pluralidade de atores individuais que interatuam entre si em uma situação que tem ao menos um aspecto físico, ou ambiental envolvido. Os atores estão motivados por uma tendência a obter o máximo de gratificações possíveis na situação e orientam sua ação com base em expectativas de papel mútuas a respeito da conduta um do outro, cada um dos quais podendo compartilhar elementos simbólicos presentes num sistema cultural comum. A relação entre esses três sistemas é destacada pelo autor:

\begin{abstract}
Esta relación fundamental entre disposiciones de necesidad de la personalidad, expectativas de rol del sistema social y pautas de valor institucionalizadas-internalizadas, es el nudo fundamental de la organización de los sistemas de la acción. Este es el punto al que se enfocan tanto ambas - la interdependência como independencia recíproca de la personalidad, el sistema social y la cultura (PARSONS, 1982, p. 497).
\end{abstract}

\footnotetext{
${ }^{3}$ Os elementos estruturais da cultura, segundo Parsons (1982), constituem-se de três sistemas simbólicos relativamente estáveis, que permitem a comunicação e a abstração de seus significados em uma determinada situação: (1) sistema de ideias ou crenças cognitivas; (2) sistema de pautas ou símbolos expressivos e (3) sistemas de pautas integrativas ou critérios de orientação de valor.
} 
Assim como Weber, ele busca conciliar as abordagens objetiva e subjetiva no entendimento da ação social. A ação humana, segundo Parsons, compreende processos motivacionais assentados não apenas numa racionalidade instrumental (no sentido econômico), mas também em mecanismos não-racionais ou irracionais, ligados aos processos de aquisição de valores pelo indivíduo. Diferenciando-se da perspectiva utilitarista, Parsons argumenta que qualquer elemento da ação insere-se numa situação com diretrizes já dadas a priori e com base nas quais o agente deve atuar. Sua vontade se vê constrangida pelos mecanismos de controle social, no caso de desvio e desrespeito a regras. Os processos pelos quais valores e normas tornam-se partes constitutivas dos sistemas de personalidade são chamados de "internalização", e dos sistemas sociais, "institucionalização". É através desse processo que se pode medir o grau de integração do sistema social, ou ao contrário, o seu reverso, ou seja, a anomia ${ }^{4}$.

Objetivamente, as instituições são vistas como padrões de orientação de valor, que regulam as relações dos indivíduos um com os outros e que definem como as relações dos indivíduos devem ser. As chamadas "pautas de valores institucionalizadas" formam o elemento estrutural central dos sistemas sociais e constituem-se, basicamente, em normas que definem quais ações e atitudes se esperam legitimamente das pessoas e, neste sentido, formam verdadeiramente parte da tradição cultural. Assim como em Durkheim, as pautas institucionalizadas definem a ação dos indivíduos em sociedade e funcionam como autoridade "moral", que têm uma influência "obrigatória" ou de controle sobre a ação, e de acordo com as quais os indivíduos se orientam em termos de crenças, valores morais, metas e desejos.

As instituições, segundo Parsons (1954; 1982; 1934/1990), são classificadas da seguinte maneira:

1. Instituições relacionais (funcionais): que definem expectativas de papel recíprocas com independência do conteúdo do interesse. A instituição, no presente sentido, consiste em pautas que governam a conduta e as relações sociais que interagem com um sistema de sentimentos morais comuns, os

\footnotetext{
${ }^{4}$ Percebe-se aqui a influência de Emile Durkheim em seu pensamento.
} 
quais, por sua vez, definem o que se deve esperar de uma pessoa em uma certa posição.

2. Instituições regulativas: que definem os limites da legitimidade da consecução de interesses "privados" em relação a fins e meios. Estas podem ser subdividas em:

a) Instrumental: integração de metas privadas com valores comuns e definição de meios legítimos;

b) Expressiva: que regulam as ações, situações, pessoas, ocasiões e cânones permissíveis;

c) Moral: que definem as áreas permitidas de responsabilidade moral para a pessoa e para a sub-coletividade.

3. Instituições culturais: que definem as obrigações de aceitar as pautas culturais, convertendo a aceitação privada em dever institucionalizado. Estas podem ser subdividas em:

a) crenças cognitivas;

b) sistemas de símbolos expressivos;

c) obrigações morais privadas.

A relação entre o novo institucionalismo e a teoria parsoniana é, nesse sentido, bastante evidente. Embora, como costumeiramente se nota, muitos autores adeptos do novo institucionalismo não reconheçam tal legado, em parte ou no todo, não mencionando Parsons e suas teorias e seus escritos. É considerável que o autor americano forneça a base e os principais pressupostos para o desenvolvimento de alguns pontos-chave da teoria 'neoinstitucional'. Tal assertiva, todavia, não nos impede de empreender uma análise comparativa mais aprofundada entre as duas abordagens, para mostrar possíveis pontos de tensão e lacunas que nelas se sobressaem. Sendo assim, passamos a explorar algumas dimensões da "teoria das instituições" de Parsons para, em seguida, mostrar como se fazem presentes na abordagem institucional da atualidade. 


\section{PARSONS E A PREOCUPAÇÃO COM UMA “TEORIA DAS INSTITUIÇÕES”}

Pode-se afirmar que Parsons, como ele mesmo reconhece, desenvolve muitos dos conceitos relativos a uma Teoria das Instituições, a partir das influências que teve de Vilfredo Pareto, Émile Durkheim, Max Weber, Georg Simmel e Ferdinand Tonnies. O marco de referência está em Prolegomena to a Theory of Social Institutions, escrito em 1934, enquanto ainda era professor do Departamento de Sociologia da Universidade de Harvard, e publicado em 1990 pela American Sociological Review.

Particularmente no artigo citado, Parsons mostra sua preocupação com a construção de uma Teoria das Instituições, ou daquilo que chama de base de tal teoria, como projeto central da sociologia. Por isso, o autor faz questão de intitular esse paper como "Prolegomena a uma Teoria das Instituições", ou seja, como uma reflexão inicial sobre o tema.

No trabalho, Parsons dedica toda a sua atenção àquilo que descreve como análise "subjetiva" das instituições, do ponto de vista da ação dos indivíduos em relação às últimas. Ele contrasta tal aspecto com a perspectiva "objetiva" das instituições, isto é, o estudo do ponto de vista do observador que trata as instituições como "formas de relação social sancionadas pela vontade geral" (PARSONS, 1934/1990, p.327, tradução nossa), uma definição que atribui ao Professor Robert Maclver.

$\mathrm{Na}$ abordagem objetiva, as instituições são vistas como um complexo de relações sociais e, nesse sentido, pode ser uma instituição social concreta ou organização. Já na abordagem subjetiva, do ponto de vista da ação dos indivíduos, concebe instituições como normas regulativas, as quais dão vida à estrutura social concreta ou organização. Tendo em vista a necessidade de superar estas visões antagonistas sobre instituições, Parsons busca nesse artigo conciliar as duas perspectivas.

Ao criticar uma abordagem essencialmente "objetiva" das instituições, que segundo ele tende a uma mera tipologia institucional, Parsons atenta para o caráter normativo daquelas, e concentra sua análise nos modos uniformes de comportamento e formas de relação que são "sancionados" e que guardam alguma 
relação significativa com os padrões normativos em maior ou menor grau aprovados pelos indivíduos sujeitos a eles (idem, p.320). Mais adiante, Parsons adverte para o perigo em identificar as instituições com aquelas formas concretas de relação social e afirma que "somente uma teoria da ação oferece os fundamentos metodológicos mais concretos e torna possível a distinção adequada entre o institucional e outros fatores envolvidos na determinação das formas concretas de relação social" (idem, p. 328, tradução nossa).

Toda sua análise é dedicada ao lugar das instituições na ação humana e, sobretudo, à relação do indivíduo com as instituições normativas da sociedade na qual está inserido. Lembrando que o termo instituição é utilizado em Parsons em referência não a uma norma regulativa única, mas a todo um sistema de normas fundado em valores comuns a todos os membros de uma dada sociedade. Trata-se, portanto, mais do que nunca, de um fenômeno moral:

The central thesis of the theory is that institutions are intimately related to,
and, in part at least, derived from ultimate value attitudes common to the
members of a community. They are thus, in a strict sense, moral phenomena.
This implies further that the primary motive for obedience to an institutional
norm lies in the moral authority it exercises over the individual (PARSONS,
1934/ 1990, p.326).

Essa discussão vem da ideia presente de que, em toda a sociedade, há um conjunto mais ou menos coerente de valores últimos que esta mesma define como desejáveis e que as instituições são primordialmente uma expressão de tais valores. As instituições constituem-se um sistema de normas, cuja função é a regulação da ação de tal maneira a conformá-la aos valores comuns últimos e atitudes de valor da comunidade.

Esse sistema de normas ao qual ele se refere possui a qualidade de tender à harmonia, ou ainda, como ele mesmo prefere, à integração. A conformidade com as normas é valorizada e os desvios são reprovados. A intervenção das sanções marca o processo de enfraquecimento dessa integração, e leva ao estado de anomia. Vale destacar que, inevitavelmente, Parsons não aborda em profundidade o problema da mudança nos sistemas de valores, e mesmo como novos elementos entram em cena em tais sistemas. Ele mesmo destaca esse ponto falho no final do texto: 
the limitations of the current state of the literature of the subject. Before we get very far in developing a theory of change, it is necessary to know what it is that changes - the principal task of this paper has been to supply that gap. It does not constitute a theory of social institutions - rather some of the necessary prolegomena to such a theory (PARSONS, 1934/1990, p. 333).

Diversos teóricos contemporâneos notam alguns tipos de limitação nas formulações parsonianas acima. Powell \& DiMaggio (1991), autores já mencionados, relegam a Parsons sua contribuição para os "microfundamentos" da teoria institucional e seu esforço em compreender as maneiras pelas quais os elementos culturais são incorporados pelos indivíduos. Mas advertem que a concepção parsoniana de cultura falhou em enfatizá-la como "um objeto de orientação para além dos indivíduos", dando assim muito mais peso ao ponto-de-vista subjetivo visà-vis ao objetivo. $\mathrm{E}$ ainda, eles argumentam que a análise da cultura feita pelo autor negligencia as dimensões cognitivas em favor dos componentes valorativos: cultura como a internalização de "orientações de valor".

Jeffrey Alexander (1990), ao comentar o artigo de Parsons, enfatiza que embora esse tenha desenvolvido uma visão multidimensional da ação social, sua concepção de institucionalização colocou muito mais peso nas relações culturais, sobredimensionando $\mathrm{O}$ controle exercido pelos valores sobre as condições (ALEXANDER, 1990, p. 344). A importância dos interesses e da ação instrumental e a escolha racional foram subestimados.

Dada a abrangência e a amplitude da obra de Parsons, não é de se surpreender a quantidade e a intensidade de outras polêmicas que suscitou. Dentre essas críticas podemos citar: sua reduzida preocupação com pesquisa empírica e o grande peso dado às grandes teorias e conceitos abstratos; as inconsistências entre a vinculação analítica dos níveis micro e macrossociais na passagem que faz da teoria da ação social ao sistema social; seu conceito limitado de racionalidade; ênfase na estabilidade dos sistemas sociais; o caráter marginal do conflito e de conceitos como poder e ideologia em sua teoria, entre outras.

De fato, como observado por Tania Quintaneiro (2002), essa é a razão pela qual alguns autores retomam criticamente aspectos da teoria parsoniana e incorporam, ao mesmo tempo, elementos das perspectivas sociológicas como as que enfatizam as temáticas do conflito, da mudança e da ideologia. Os trabalhos de 
Robert Merton, bem como da chamada corrente neofuncionalista, devem ser visto na esteira do novo interesse despertado pela sociologia parsoniana que se desponta na década de 80. Cita ainda como exemplo Jeffrey Alexander que, embora crítico do viés conservador, do formalismo e da inabilidade da teoria sistemática de Parsons para tratar conflitos e mudanças históricas, reconhece a sua importância para a sociologia do pós-guerra. Este autor enfatiza a necessidade de ser rever a relação micro-macro, sua síntese e reintegração, bem como de se promover meios que integrem teoria e pesquisa empírica.

A autora ainda cita exemplos de outros trabalhos que buscam essa síntese teórica, como as abordagens da microssociologia ou das microinterações simbólicas, implícitas na teoria da trocas (George C. Homans, Peter Blau), o interacionismo simbólico (Herbert Blumer, George H. Mead, Erving Goffman), a teoria da ordem negociada (Anselm Strauss), a etnomedologia (Harold Garfinkel, Alan Cicourel), que representam um avanço face aos pontos frágeis da análise de Parsons. Cada uma destaca, a seu modo, a criatividade, a autonomia e a racionalidade que, presentes nas escolhas dos indivíduos, seriam capazes de modificar as regras preestabelecidas, de dar-lhes novos significados e redefini-las no decorrer da interação. Tais perspectivas, fundadas no individualismo metodológico, "questionam a capacidade da sociologia parsoniana de predição de conduta e de explicação dos fenômenos sociais, com base no poder de normas prescritas, e acentuam o caráter processual da ação, a intervenção do agente dotado de subjetividade, o diálogo, a reflexão, a reconstituição contínua das instituições por meio da controvérsia, do acordo e da tolerância, o caráter provisório dos objetivos e normas, a contextualização e, em suma, tudo o que teria a ver com a transitoriedade da ordem social e que se vincula aos elementos da rebeldia e arbítrio contidos nas ações humanas" (QUINTANEIRO, 2002, p.192).

O campo de estudos institucionalistas também é marcado por essa dificuldade de síntese teórica, como colocado acima. Como exemplo de tentativas de desenvolvimento de uma nova perspectiva sobre as instituições, é interessante referir o esforço intelectual feito por Maria C. Misocsky (2003), que inclusive cita os trabalhos de Leslie S. Oakes, Barbara Townley e David J. Cooper (1998) para ampliar o referencial institucional, utilizando para isso aspectos da filosofia da ação 
de Pierre Bourdieu (2005), principalmente as noções de campo social e campo de poder ${ }^{5}$. Para a autora, utilizar as formulações desse autor implica romper com uma tradição de estudos organizacionais. Implica ainda, romper com outra tradição, a do estruturalismo, que subestima o papel dos sujeitos. Em vez disso, propõe "analisar as posições dos agentes em campos construídos por disputas entre detentores de recursos de poder, como condição essencial para compreender a dinâmica de campos organizacionais, entendidos, agora, como espaço de força e de lutas" (MISOCSKY, 2003, p.170).

De fato, do ponto de vista metodológico, o que se pode notar na maioria dos artigos de autores que vinculam à perspectiva institucional, são pesquisas mais quantitativas do que qualitativas, e que buscam relações e regularidades entre atributos (peso dos mecanismos institucionais). Isto parece adequado à análise sincrônica de casos bem delimitados, com uma estabilidade institucional relativamente elevada. No entanto, a extrema mutabilidade dos "arranjos institucionais" que constrangem as escolhas dos atores, em alguns processos sociais, econômicos e políticos, parecem reivindicar uma abordagem mais orientada à historicidade dos fenômenos. Essa é uma das tensões ainda presentes nas abordagens do novo institucionalismo, cujos desdobramentos retratamos a seguir.

\section{AS ABORDAGENS DO NOVO INSTITUCIONALISMO ${ }^{6}$}

A abordagem institucional, sobretudo na versão do chamado "novo institucionalismo", vem sendo amplamente utilizada para designar uma perspectiva teórica que atualmente atrai muita atenção, e também certas críticas. Na literatura especializada, essa perspectiva teórica é apontada como uma tentativa de se

\footnotetext{
${ }^{5}$ Pierre Bourdieu propõe uma filosofia da ciência, que ele chama de relacional; e uma filosofia da ação (que ele chama de disposicional) cujo eixo central é a relação entre as estruturas objetivas e as estruturas incorporadas (condensado por conceitos como "habitus" e "campo"). Dos conceitos que compõem a metodologia de Bourdieu, a noção de "campo" mostra-se fundamental, entendido como espaço onde se trava uma luta concorrencial entre os agentes em torno de interesses específicos (capitais específicos): "É isso que acredito expressar quando descrevo o espaço social como um campo, isto é, ao mesmo tempo, como um campo de forças, cuja necessidade se impõe aos agentes que nele se encontram envolvidos, e como um campo de lutas, no interior do qual os agentes se enfrentam, com meios e fins diferenciados conforme sua posição na estrutura do campo de forças, contribuindo assim para a conservação ou a transformação de sua estrutura" (BOURDIEU, 2005, p.50).

${ }^{6}$ Este subitem expõe o referencial teórico utilizado como arcabouço para a descrição e compreensão do fenômeno estudado em nossa tese de doutorado.
} 
contrapor ao modelo racionalista e seu foco nas exigências técnicas dos processos gerenciais e produtivos, ao voltar sua atenção para o exame dos elementos de redes relacionais e de sistemas culturais que modelam e sustentam a estrutura e a ação das organizações (FONSECA, 2003).

Cabe destacar que a abordagem neoinstitucionalista possui algumas particularidades que a diferencia de muitas construções explicativas clássicas. No campo da Ciência Política, por exemplo, as diferenças mais significativas do neoinstitucionalismo em relação a outras abordagens, estão relacionadas ao nexo explicativo dos processos e fenômenos políticos. As diversas perspectivas analíticas conhecidas como neoinstitucionalistas identificam as instituições (compreendidas como elementos autônomos) enquanto variáveis independentes com capacidade explicativa sobre os resultados políticos concretos e determinação sobre alguns traços do comportamento sócio-político dos indivíduos e dos grupos. Como coloca Fernando Limongi:

O que esta literatura sugere é que as regras, leis, procedimentos, normas, arranjos institucionais e organizacionais implicam a existência de constrangimentos e limites ao comportamento. Em última análise, estes constrangimentos e limites acabam por explicar os próprios resultados do comportamento (LIMONGI, 1994, p.08).

Dessa forma, como explica Fabrício Tomio (2002), a abordagem neoinstitucionalista seria distinta de outras construções explicativas baseadas em causas societais, tais como a pluralista, as perspectivas marxistas, a análise sistêmica, etc., que têm em comum a explicação dos resultados políticos por fatores sociais. Para essas abordagens, as transformações na esfera política (institucionais ou não) resultariam das características estruturais da esfera sócio-econômica, ou da capacidade conjuntural de determinados grupos em mobilizar recursos e fazer pressão para ter seus interesses políticos atendidos, ou, ainda, de aspectos comportamentais dos atores envolvidos no processo de decisão política. Em síntese, os elementos inerentes ao espaço da política e sua dinâmica seriam variáveis dependentes dos fatores sociais.

Dentro dos estudos organizacionais, a perspectiva neoinstitucional surge principalmente a partir dos estudos de Philip Selznick, discípulo de Robert Merton, e retomou fôlego nas décadas de 70/80 (século XX), a partir dos trabalhos de John 
Meyer e Brian Rowan, Paul DiMaggio e Walter Powell, Lynne Zucker, W. Richard Scott entre outros ${ }^{7}$. Sucintamente, pode-se dizer que a abordagem institucional às organizações enfatiza: a) a dependência ambiental da estrutura organizacional; b) as dimensões política e cultural envolvidas; e c) os efeitos dessas dependências na definição da natureza de organizações mais modernas, particularmente a natureza fluída e complexa de organizações criadas. A ênfase desses estudos é colocada nas instituições, enquanto variável independente. A questão dos valores, da busca pela legitimidade e do isomorfismo é colocada em destaque na análise sobre relações entre organizações, e entre organizações e ambiente (VIEIRA \& CARVALHO, 2003).

Cabe ressaltar que o neoinstitucionalismo não consiste apenas em uma nova versão do antigo institucionalismo, mas também uma tentativa de continuação. Qualquer revisão da literatura, por mais superficial que seja, mostrará que tanto o novo como o velho institucionalismo, compartilham da ênfase nas instituições, regras, procedimentos etc. e destacam a relação das organizações com o ambiente mais geral. No entanto, em que pese a importância dada às instituições no interior de seu arcabouço teórico explicativo, os institucionalistas ou neoinstitucionalistas não apresentam, ou mesmo se preocupam em apresentar, uma definição precisa do que se deve entender por "instituições", por mais paradoxal que isso possa parecer.

Uma grande parte dessa confusão que cerca o neoinstitucionalismo desaparece quando se admite que não constitui em si uma corrente de pensamento unificada, que reflete em diferentes perspectivas analíticas e arranjos metodológicos diversos. O único ponto de convergência é opção pelo individualismo metodológico, mas mesmo assim há uma pequena diferença entre elas, uma vez que partem de pressupostos distintos sobre a racionalidade e comportamento dos atores. Segundo Peter Hall e Rosemary Taylor (2003), as diferenças entre as suas principais abordagens se manifestam nos três tipos de "institucionalismos" que se depreende

\footnotetext{
7 Philip Selznick, "TVA and the grass roots" (Berkeley: University of California Press, 1949). Uma consolidação das conclusões teóricas desse autor foi feita por Meyer e Rowan, "Institutionalized organizations: formal structures as mith and ceremony" (American Journal of Sociology, n.83, 1977); Lynne G. Zucker, "The role of institutionalization in cultural persistence" (American Sociological Review, n.42, 1977); Paul DiMaggio e Walter Powell, "The iron cage revisited: institutional isomorphism and collective reality in organizational fields" (American Sociological Review, n.48, 1983). John Meyer e Richard Scott (Eds.), "Organizational environments: ritual and rationality" (London: Sage, 1983). Para outros exemplos importantes da teoria institucional nas organizações, ver Walter Powell e Paul DiMaggio (Eds.), "The new institutionalism in organizational analysis" (Chicago: University of Chicago Press, 1991) e W. R. Scott, "Institutions and Organizations" (Thousand Oaks, CA: Sage Publications, 1995).
} 
nesses estudos: o institucionalismo histórico, o sociológico e o institucionalismo de escolha racional.

O quadro a seguir expõe, de forma simplificada, as principais diferenças entre essas três perspectivas:

\begin{tabular}{|c|c|c|c|}
\hline $\begin{array}{c}\text { Tipos de } \\
\text { Distinções }\end{array}$ & $\begin{array}{l}\text { INSTITUCIONALISMO DA } \\
\text { “ESCOLHA RACIONAL” }\end{array}$ & $\begin{array}{l}\text { INSTITUCIONALISMO } \\
\text { "HISTÓRICO" }\end{array}$ & $\begin{array}{l}\text { INSTITUCIONALISMO } \\
\text { "SOCIOLÓGICO" }\end{array}$ \\
\hline & 1) Abordagem Dedutiva & 1) Abordagem Indutiva & 1) Abordagem Indutiva \\
\hline & $\begin{array}{l}\text { 2) Realiza comparações de } \\
\text { poucos aspectos em muitos } \\
\text { casos }\end{array}$ & $\begin{array}{l}\text { 2) Realiza comparações de } \\
\text { muitos aspectos em poucos } \\
\text { casos }\end{array}$ & $\begin{array}{l}\text { 2) Realiza comparações de } \\
\text { muitos aspectos em poucos } \\
\text { casos }\end{array}$ \\
\hline Metodológicas & $\begin{array}{l}\text { 3) Realça o aspecto preditivo } \\
\text { da teoria através da } \\
\text { consolidação de hipóteses } \\
\text { verificáveis positivamente. }\end{array}$ & $\begin{array}{l}\text { 3) Não realça o aspecto } \\
\text { preditivo, mas sim o aspecto } \\
\text { descritivo-explicativo, através } \\
\text { da compreensão do processo } \\
\text { diacrônico e do contexto } \\
\text { histórico nos casos } \\
\text { investigados. }\end{array}$ & $\begin{array}{l}\text { 3) Explicação causal dos } \\
\text { fenômenos sociais através da } \\
\text { análise diacrônica e do } \\
\text { contexto histórico-cultural dos } \\
\text { fatos investigados. }\end{array}$ \\
\hline \multirow{2}{*}{$\begin{array}{l}\text { Influência: } \\
\text { instituições } X \\
\text { atores sociais }\end{array}$} & $\begin{array}{l}\text { 1) Instituições constrangem as } \\
\text { estratégias mas não } \\
\text { determinam as preferências } \\
\text { individuais. }\end{array}$ & $\begin{array}{l}\text { 1) Instituições influenciam não } \\
\text { apenas os cálculos } \\
\text { estratégicos dos indivíduos, } \\
\text { mas também suas } \\
\text { preferências mais } \\
\text { fundamentais. }\end{array}$ & $\begin{array}{l}\text { 1) Instituições influenciam não } \\
\text { apenas os cálculos } \\
\text { estratégicos dos indivíduos, } \\
\text { mas também suas } \\
\text { preferências mais } \\
\text { fundamentais. }\end{array}$ \\
\hline & $\begin{array}{l}\text { 2) Individualismo } \\
\text { metodológico baseado na } \\
\text { Teoria da Escolha Racional. }\end{array}$ & $\begin{array}{l}\text { 2) Individualismo } \\
\text { metodológico com aceitação } \\
\text { de aspectos estruturantes nas } \\
\text { condutas individuais (políticos, } \\
\text { sociais, históricos e culturais). }\end{array}$ & $\begin{array}{l}\text { 2) Individualismo } \\
\text { metodológico, baseado no } \\
\text { enfoque culturalista. }\end{array}$ \\
\hline $\begin{array}{l}\text { Conceito de } \\
\text { Instituições }\end{array}$ & $\begin{array}{l}\text { 1) regras, procedimentos ou } \\
\text { normas formais. }\end{array}$ & $\begin{array}{l}\text { 1) procedimentos, protocolos, } \\
\text { normas e convenções formais } \\
\text { e informais inerentes à } \\
\text { estrutura organizacional da } \\
\text { comunidade política ou da } \\
\text { economia política. }\end{array}$ & $\begin{array}{l}\text { 1) inclui não somente as } \\
\text { regras, procedimentos ou } \\
\text { normas formais, mas também } \\
\text { os sistemas de símbolos, os } \\
\text { esquemas cognitivos e os } \\
\text { modelos morais que fornecem } \\
\text { "padrões de significação" que } \\
\text { guiam a ação humana. }\end{array}$ \\
\hline
\end{tabular}

QUADRO 1: Distinções entre as correntes teóricas neoinstitucionalistas

FONTE: Adaptado de TOMIO (2002); HALL \& TAYLOR (2003). 
Segundo Hall e Taylor (2003, p.194), o “institucionalismo histórico" desenvolveu-se como reação contra a análise da vida política em termos de grupos (também sob a forma de variantes pluralistas e neo-marxistas) e contra o estruturofuncionalismo, que dominavam a ciência política nos anos 60 e 70 . Segundo seus adeptos $^{8}$, o único modo de analisar cientificamente os fenômenos políticos residiria no estudo dos comportamentos empiricamente observáveis (por isso também são chamadas de vertentes "comportamentalistas"), uma vez que revelariam ao analista as preferências reais dos atores políticos e a intensidade dessas mesmas preferências.

De forma muito geral, como enfatiza Renato M. Perissinotto (2004), a crítica do neoinstitucionalismo a essas correntes consiste em recusar a identificação que seus teóricos fazem entre as preferências manifestas dos atores e as suas preferências reais e defender que a análise política deve se preocupar em saber como tais preferências se relacionam com as instituições políticas. Para os institucionalistas históricos, as instituições afetam as preferências dos atores. Assim, o que os atores dizem preferir pode não ser a manifestação de suas preferências reais e sim aquilo que é possível preferir num dado contexto institucional, mas não em outro. Mas como os teóricos do institucionalismo histórico definem "instituições"? De modo geral como os procedimentos, rotinas, normas sociais, convenções ou legados de política que constrangem as estratégias e determinam as preferências dos atores (suas estratégias e metas).

Já os estudos institucionalistas ancorados na escolha racional enfatizam o papel das regras e procedimentos formais que constituem o contexto estratégico que delimita a interação dos atores (mas não determinam suas preferências individuais). Para o institucionalismo de escolha racional, os atores respondem racionalmente ao contexto institucional, usando de forma estratégica as regras do jogo com vistas sempre a maximizarem os seus interesses. Segundo George Tsebelis,

\footnotetext{
A abordagem da escolha racional centra-se nas coerções impostas aos atores racionais - as instituições de uma sociedade. Parece paradoxal que o enfoque da escolha racional não esteja preocupado com os indivíduos ou atores e centre a sua atenção nas instituições políticas e sociais. A razão

${ }^{8}$ Sobre o "institucionalismo histórico" consultar Thelen \& Steinmo. In: STEINMO, S.; THELEN, K.; LONGSTRETH, F. (Eds). Structuring Politics: Historical Institutionalism in comparative analysis. Cambridge: Cambridge University Press, 1994.
} 
desse paradoxo é simples: assume-se que a ação individual é uma adaptação ótima a um ambiente institucional e se sustenta que a interação entre os indivíduos é uma resposta otimizada na relação recíproca entre ambos. Assim, as instituições predominantes (as regras do jogo) determinam o comportamento dos atores, os quais, por sua vez, produzem resultados políticos e sociais. (TSEBELIS, 1998, p. 51)

Essa idéia de ator racional está presente na maioria dos estudos da ciência política contemporânea e também nos estudos emprestados à "nova economia da organização", que insiste na importância dos direitos de propriedade, das rendas e dos custos de transação para o desenvolvimento e o funcionamento das instituições. Uma tese particularmente influente foi a desenvolvida por Oliver Williamson ${ }^{9}$, para quem o desenvolvimento de uma dada instituição, por exemplo, os aspectos organizacionais de uma empresa, podem ser compreendidos como um esforço para reduzir os custos de transação e as incertezas presentes em qualquer forma de intercâmbio.

Hall e Taylor (2003), por sua vez, destacam que o institucionalismo da escolha racional, em sua origem, surgiu no contexto do estudo de comportamentos no interior do Congresso dos Estados Unidos. De maneira geral, tais trabalhos buscavam explicar como os regulamentos do Congresso afetavam o comportamento dos legisladores e por que foram adotados, com especial atenção ao sistema de comissões do Congresso e às relações entre o Congresso e as autoridades administrativas independentes. Destacam, nessa direção, os trabalhos de Gary W. Cox, Mathew D. McCubbins, entre outros. Por outro lado, a partir dos anos 90 os teóricos da escola da escolha racional interessaram-se também pela explicação de certo número de outros fenômenos políticos, entre os quais o comportamento das coalizões segundo os países, o desenvolvimento histórico das instituições políticas e a intensidade dos conflitos étnicos.

Os institucionalistas históricos, bem como os da vertente sociológica, criticam a perspectiva "calculadora" do comportamento humano na teoria da escolha racional. Para os teóricos do institucionalismo histórico, o pressuposto da racionalidade presente na "teoria dos jogos", ainda que aceitável, é muito limitado e, por isso, o analista deve ir além dele para realizar uma análise efetiva das decisões

\footnotetext{
${ }^{9}$ A esse respeito, ver O. Williamson, Markets and Hierarchies. New York: Free Press, 1975, e do mesmo autor, The Economic Institutions of Capitalism. New York: Free Press, 1985.
}

Cad. de Pesq. Interdisc. em Ci-s. Hum-s., Florianópolis, v.10, n.97, p. 181-204, jul./dez. 2009 
tomadas, com aceitação de outros aspectos estruturantes nas condutas individuais (tais como os políticos, sociais, históricos e culturais). Lembrando que para esta corrente teórica, as instituições não se constituem apenas num contexto perante o qual atores racionais reordenam suas preferências. Mais do que isso, elas são fundamentais na definição mesma do conteúdo dessas preferências. Por essa razão, os atores devem ser vistos menos como maximizadores de interesses e mais como indivíduos que visam adequar seus comportamentos às normas institucionais, menos como homo economicus e mais como homo sociologicus (PERISSINOTTO, 2004).

Essa ideia aproxima-se muito da perspectiva sociológica (ou cultural), que trata dessas questões de modo diferente, ao sublinhar que o comportamento é limitado pela cultura, visão do mundo e experiência de cada indivíduo. Em outros termos, embora reconhecendo que o comportamento humano é racional e orientado para fins, ele enfatiza o fato de que os indivíduos recorrem com freqüência a protocolos estabelecidos ou a modelos de comportamento já conhecidos para atingir seus objetivos. Ela tende a considerar os indivíduos como satisficers mais do que como optimizers (HALL \& TAYLOR, 2003), e a salientar até que ponto a escolha de uma linha de ação depende da interpretação de uma situação mais do que de um cálculo puramente utilitário.

Hall \& Taylor (2003), destacam três características fundamentais do institucionalismo em Sociologia, que Ihe confere certa originalidade relativamente às outras variedades do "neoinstitucionalismo":

a) Primeiro, os teóricos dessa escola tendem a definir as instituições de maneira muito mais global do que os pesquisadores em Ciência Política, incluindo não só as regras, procedimentos ou normas formais, mas também os sistemas de símbolos, os esquemas cognitivos e os modelos morais que fornecem "padrões de significação" que guiam a ação humana. Scott (1994), por exemplo, que sugere uma das definições mais populares de instituições, diz que: "Institutions are symbolic and behavioral systems containing respresentational, constitutive, and normative rules together with regulatory mechanisms that define a commom meaning system and give rise to distinctive actors and action routines" (SCOTT, 1994, p.68). Dessa posição derivam duas conseqüências importantes. Em primeiro lugar, rompe a 
dicotomia conceitual que opõe "instituições" e "cultura", levando-as à interpenetração. E, em segundo, esse enfoque tende a redefinir a "cultura" como sinônimo de "instituições"10.

b) Em segundo lugar, os novos institucionalismos sociológicos distinguem-se igualmente pelo seu modo de encarar as relações entre as instituições e a ação individual. Nesse sentido, as instituições exercem influência sobre o comportamento não simplesmente ao especificarem o que se deve fazer, mas também o que se pode imaginar fazer num contexto dado. Em tal ponto pode-se constatar a influência do construtivismo social sobre o neoinstitucionalismo sociológico.

c) Por fim, os novos institucionalismos sociológicos distinguem-se pela sua maneira de tratar do problema da explicação do surgimento e da modificação das práticas institucionais. Eles sustentam que as organizações adotam com freqüência uma nova prática institucional por razões que têm menos a ver com o aumento da sua eficiência ("lógica instrumental”), do que com reforço que oferece a sua legimitidade social à de seus adeptos ("lógica das conveniências"). Em outros termos, as organizações adotam formas e práticas institucionais particulares porque têm um valor largamente reconhecido num ambiente cultural mais amplo.

De acordo com Scott (1995), a origem do institucionalismo na teoria sociológica foi inspirada em dois grandes intelectuais: Durkheim e Weber. Em Durkheim as instituições sociais são equivalentes aos sistemas simbólicos, entendidos como sistema de crenças, representações coletivas, moral. Já em Weber, embora o conceito de instituição não esteja explícito, sua preocupação é compreender a maneira pela qual valores culturais definem estruturas sociais $\mathrm{e}$ governam a ação dos indivíduos, incluindo estruturas econômicas e comportamentos.

Em relação ao novo institucionalismo sociológico, Hall \& Taylor (2003) advogam que esse surge no quadro da teoria das organizações. Esse movimento remonta ao fim dos anos 70 , no momento em que sociólogos puseram-se a

\footnotetext{
${ }^{10}$ Destacam, nesse sentido, os trabalhos de G. Almond e S. Verba, The Civic Culture. Boston: Little Brown, 1963; L. Zucker, The Role of Institutionalization in Cultural Persistence. In: Powell \& DiMaggio. The New Institutionalism in Organizational Analysis. Chicago: University of Chicago Press, 1991, p. 83-107); A. Swidler. Culture in Action: Symbols and Strategies. American Sociological Review, 51, 1986, p. 273-286. Também J. March e J. P. Olsen. Rediscovering Institutions: The Organizational Basis of Politics. New York: Free Press, 1989, dentre outros.
} 
contestar a distinção tradicional entre a esfera do mundo social, vista como o reflexo de uma racionalidade abstrata de fins e meios (de tipo burocrático) e as esferas influenciadas por um conjunto variado de práticas associadas à cultura. Dada a sua ótica própria, os institucionalistas em geral escolhem uma problemática que envolve a explicação de por que as organizações adotam um específico conjunto de formas, procedimentos ou símbolos institucionais, com particular atenção à difusão dessas práticas.

Diversos autores atribuem a Philip Selznick ${ }^{11}$ (discípulo de Merton e descendente intelectual de Michels e Barnard), o precursor da perspectiva institucional no campo da sociologia das organizações (COLIGNON, 1997, POWELL \& DIMAGGIO, 1991, FACHIN \& MENDONÇA, 2002). Conforme Roberto Fachin e Ricardo Mendonça:

A perspectiva institucional pode ser tipificada como uma abordagem simbólico-interpretativa da realidade organizacional, apresentando uma posição epistemológica predominantemente subjetivista, em que é salientada a construção social da realidade organizacional (FACHIN \& MENDONÇA, 2002, p.29).

Como já dito anteriormente, as raízes dessa perspectiva vêm desde Durkheim, passando por Weber, Simmel, Tonnies, Parsons, e posteriormente nos trabalhos de Robert Merton. Em que pese as críticas sobre Parsons, é importante salientar que ele abriu um espaço significativo no campo da Teoria das Organizações (ou Sociologia das Organizações). Segundo Misocsky (2003, p.158), a influência de Parsons se reflete em vários aspectos: ênfase na cognição e na motivação do comportamento organizacional; poder que existe ou sobrevive somente se é legitimado pela sociedade, o que confere um manto de moralidade para a organização, foco na ordem e na reprodução, mudança como processo evolutivo, vínculo entre normas do ambiente e estrutura organizacional.

Maria Misocsky (idem) compara os aspectos que compõem as formulações de Parsons e as de DiMaggio e Powell (dois outros autores de referência nos estudos organizacionais), e mostra como algumas das preocupações parsonianas

\footnotetext{
${ }^{11}$ Dois textos de Selznick encontram-se entre as obras mais citadas da literatura em teoria das organizações: TVA and The Grass Roots. New York: Harper \& Row, 1949, e Leadership in Administration. New York: Harper \& Row 1957, este último com edição em português (Liderança em Administração. Rio de Janeiro, FGV: 1971).
} 
são precursoras das abordagens contemporâneas que esses dois autores discutem: preocupação com o modo como a ordem social pode ser legitimada, ênfase nos processos normativos, sistema social como uma pluralidade de atores individuais interagindo em uma estrutura ou ambiente, o interesse como motivação para a ação, a ação vista pela ótica do comportamento reativo fundada na cultura, a relação entre os atores e destes com o ambiente etc.

A influência de Parsons nos estudos organizacionais também se encontra na apresentação que Scott (1995) faz dos três pilares da teoria institucional contemporânea: os pilares normativo, cognitivo e regulativo. Este autor define o pilar regulativo como aquele que enfatiza a capacidade em estabelecer regras, inspecionar ou revisar a conformidade a estas, manipular sanções ou recompensas. Nesse sentido, as instituições constrangem e regulamentam o comportamento. Economistas, incluindo os historiadores econômicos são particularmente seguidores dessa visão de instituições. Um segundo grupo de teóricos vê as instituições a partir do pilar normativo, que enfatiza valores que introduzem uma dimensão prescritiva, avaliativa e obrigatória na vida social. Sistemas Normativos incluem valores e normas. Os valores definem concepções do desejável junto com a construção de padrões com os quais estruturas ou comportamentos existentes podem ser comparados ou avaliados. As normas especificam como as coisas devem ser feitas; definem meios legítimos para perseguir fins valorizados. Assim, os atores se adequam não porque isto é conveniente aos seus interesses pessoais, mas porque é o esperado. É sob este pilar normativo que estaria Parsons, ao lado de Durkheim e Selznick. Já um terceiro grupo de institucionalistas, principalmente antropólogos como Clifford Geertz e sociólogos como Berger e Luckman, Meyer e Zucker, enfatizam os elementos cognitivos das instituições: a importância dos símbolos (palavras, significados e gestos) e dos processos de construção social de realidades.

Por trazer estas e outras discussões, Parsons pode ser considerado um autor de referência no campo da teoria sociológica das instituições, embora seu referencial teórico-metodológico seja pouco citado ou pouco comentado. Apesar das críticas feitas a sua teoria, a contribuição parsoniana para o entendimento da concepção normativa das instituições continua até os dias de hoje. Outros 
rebatimentos suscitados pelas propostas teóricas parsonianas mais gerais poderiam aqui ser mencionadas, sejam na forma de crítica, aplicação ou desenvolvimento de suas ideias. No entanto, como não é possível esgotar aqui todas as dimensões de sua influência, a intenção é que esse breve exercício de aproximação entre a teoria institucional e os escritos de Parsons possa servir ao debate sobre o pensamento sociológico clássico.

\section{CONCLUSÕES}

O objetivo do presente trabalho foi contribuir para a compreensão dos conceitos parsonianos que orientam o desenvolvimento e a consolidação da abordagem institucional. Para tanto, procurou-se, sobretudo, demonstrar que esse precursor trouxe contribuições importantes para o que se entende por "instituições" e "ambiente" na atualidade, ao enfatizar a relevância em se considerar a influência de padrões socioculturais e padrões normativos que orientam a conduta dos indivíduos.

Sob esse prisma, tornou-se possível recuperar, ainda que muito brevemente, a noção parsoniana dos sistemas gerais da ação, que se constituem de conjuntos organizados que orientam a conduta de um agente individual em uma dada situação, como o sistema social, a cultura, as normas, os valores, os papéis.

No entanto, como vem sendo observado por alguns autores, faz-se imortante salientar a necessidade de ampliar alguns dos argumentos parsonianos e suprir algumas lacunas que ainda estão presentes nos estudos do chamado novo institucionalismo. Entre eles, podem-se incluir: a dinâmica do poder e do conflito, o modo como os indivíduos modelam o contexto ambiental, a variação e o surgimento de novos arranjos institucionais, etc. Considera-se que diversas perspectivas metodológicas poderiam ser abertas para uma melhor compreensão dos fenômenos sociais, políticos e institucionais. Certamente, novos viéses seriam produzidos, porém, enfrentar as limitações explicativas, presentes em quaisquer abordagens das Ciências Sociais e Humanas, faz parte do ofício do cientista social, não sendo possível se eximir de procurar, criticamente, os melhores meios analíticos no trabalho de investigação. 


\section{REFERÊNCIAS}

ALEXANDER, Jeffrey C. Commentary: structure, value, action. American Sociological Review, v.55, n.3, p. 339-345, 1990.

BOURDIEU, Pierre. Razões práticas: sobre a teoria da ação. 6.ed. São Paulo: Papirus, 2005.

BRINTON, Mary C.; NEE, Victor. The new institutionalism in sociology. New York: Russell Sage Foundation, 1998.

COLIGNON, Richard. Power Plays: critical events in the institutionalization of the Tennessee Valley Authority. Albany: State University of New York, 1997.

FACHIN, Roberto C.; MENDONÇA, J. Ricardo C. de. Selznick: uma visão da vida e da obra do precursor da perspectiva institucional na teoria organizacional. In: VIEIRA, M. M. F.; CARVALHO, C. A. (Orgs.). Organizações, instituições e poder no Brasil. Rio de Janeiro: Editora FGV, 2003. p. 30-45.

FONSECA, Valéria S. da. A abordagem institucional nos estudos organizacionais: bases conceituais e desenvolvimentos contemporâneos. In VIEIRA, M. M. F.; CARVALHO, C. A. (Orgs.). Organizações, instituições e poder no Brasil. Rio de Janeiro: Editora FGV, 2003. p. 47-66.

LIMONGI, Fernando. O Novo Institucionalismo e os Estudos Legislativos: a literatura americana recente. BIB, Rio de Janeiro, n. 37, p. 3-38, $1^{\circ}$ sem. 1994.

HALL, Peter A.; TAYLOR, Rosemary C. R. As três versões do neo-institucionalismo. Lua Nova, São Paulo, n.58, p.193-223, 2003.

HEYDEBRAND, Wolf V. New Organizational Forms. Work and Occupations, v.16, n. 3, p. 323-357, 1989.

MAYHEN, Leon $\mathrm{H}$. Talcott Parsons: on institutions and social evolution. Chicago: The University of Chicago Press, 1982.

MISOCZKY, Maria C. Poder e Institucionalismo: uma reflexão crítica sobre as possibilidades de interação paradigmática. In VIEIRA, M. M. F.; CARVALHO, C. A. (Orgs.). Organizações, instituições e poder no Brasil. Rio de Janeiro: Editora FGV, 2003. p. 141-176.

OAKES, Leslie S.; TOWNLEYM, Barbara; COOPER; David J. Business planning as pedagogy: language and control in a changing institutional field. Administrative Science Quaterly, v. 43, n.2, p.257-292, 1998.

PARSONS, Talcott. PARSONS, T. The Structure of Social Action. New York: Macmillan, 1937. 
. Ensayos de Teoria Sociologica. Paidos: Cabildo, Buenos Aires, 1954.

Sociological Theory and Modern Society. New York: Free Press, 1967.

. O conceito de sistema social. In: CARDOSO, Fernando H.; IANNI, Octávio (Org.). Homem e Sociedade: leituras básicas de sociologia geral. São Paulo: Companhia Editora Nacional, 1973a. p.47-55.

. Os componentes do sistema social. In: CARDOSO, Fernando H.; IANNI, Octávio (Org.). Homem e Sociedade: leituras básicas de sociologia geral. São Paulo: Companhia Editora Nacional, 1973b. p.56-59.

. El Sistema Social. Madrid: Alianza Editorial, 1982.

. Prolegomena to a theory of social institutions. American Sociological Review, v.55, n.3, p. 319-339, 1990.

PERISSINOTTO, Renato M. Política e Sociedade: por uma volta à Sociologia Política. Revista Política e Sociedade, Florianópolis, v. 5, p. 201-230, out. 2004.

POWELL, Walter W.; DIMAGGIO, Paul J. (Org.). The New Institutionalism in Organizational Analysis. Chicago: University of Chicago Press, 1991.

QUINTANEIRO, Tania. Labirintos Simétricos: introdução à teoria sociológica de Talcott Parsons. Belo Horizonte: Editora UFMG, 2002.

ROCHER, Guy. Talcott Parsons e a sociologia americana. Rio de Janeiro: Franscisco Alves, 1976.

SCOTT, W. Richard. Institutions and Organizations: Toward a Theoretical Synthesis. In: SCOTT, W. R.; MEYER, J. W. (Eds.). Institutional Environments and Organizations: Structural Complexity and Individualism. Thousand Oaks, CA: Sage Publications, 1994. p. 55-80.

SCOTT, W. Richard. Institutions and Organizations. London: Sage, 1995.

TOMIO, Fabrício R. L. Comentários sobre a abordagem neoinstitucionalista. Revista Salamanca, Blumenau, n. 01, p. 17-21, jun. 2002.

TSEBELIS, George. Jogos Ocultos: escolha racional no campo da política comparada. São Paulo: EDUSP, 1998.

VIEIRA, Marcelo M. F.; CARVALHO, Cristina A. (Orgs). Organizações, instituições e poder no Brasil. Rio de Janeiro: FGV, 2003.

Artigo:

Recebido em: 18/08/2009

Aceito em: 26/10/2009 